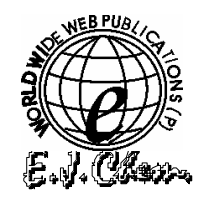

\title{
Cobalt and Nickel Complexes Bearing 2-(2-pyridyl)- Benzimidazole: Synthesis and Ethylene Oligomerization
}

\author{
JIAN-LONG DU and LI-JUN-LI* \\ College of Chemistry \& Environmental Science, \\ Hebei University, Baoding 071002, China
}

Received 10 May 2005; Accepted 31 May 2005

\begin{abstract}
A series of cobalt and nickel complexes $\operatorname{MLX}_{2}(\mathrm{M}=\mathrm{Co}$ or $\mathrm{Ni}, \mathrm{X}=\mathrm{Cl})$ bearing 2-(2-pyridyl)benzimidazole ligands were synthesized. Treatment of the complexes with methylaluminoxane (MAO) leads to active catalysts for ethylene oligomerization. The oligomers were olefins from $\mathrm{C}_{4}$ to $\mathrm{C}_{6}$.
\end{abstract}

Key words: Nickel; Cobalt; Benzimidazole; Ethylene oligomerization

\section{Introduction}

Olefin polymerization and oligomerization promoted by transition metal complexes have drawn much attention in both academic research and industrial applications. ${ }^{1-2}$ Recent progress was reported by Brookhart and co-workers who showed that $\mathrm{Ni}(\mathrm{II})$ and $\mathrm{Pd}(\mathrm{II})$ complexes bearing bulky ádimine ligands convert both ethylene and óolefins to high molecular mass polymers with varying and controllable degrees of branching. ${ }^{3-4}$ Moreover, in parallel studies, Brook hart, Bennett and Gibson groups reported highly active polymerization catalysts based on $\mathrm{Fe}(\mathrm{II})$ and $\mathrm{Co}$ (II) incorporating 2,6bis(imino)pyridyl ligands. ${ }^{5-6}$ Grubbs group reported new neutral Ni(II) salicylaldiminato complexes as catalyst for the polymerization of ethylene under moderate conditions. ${ }^{7}$ Modification the substituents of aryl and imine carbon ligand result in dramatic changes to the activity of the catalyst and physical properties of the polyolefin. ${ }^{8-10}$ We were interested in exploring the effect of changing the central moiety to other nitrogen-containing heterocycles. ${ }^{11}$ Here we describe the synthesis of $\mathrm{Co}(\mathrm{II})$ and $\mathrm{Ni}(\mathrm{II})$ complexes bearing 2-(2-pyridyl) benzimidazole ligands, as well as their oligomerization of ethylene study with MAO as co-catalyst. 
<smiles>[R]c1cc(N)c([R])cc1N</smiles>

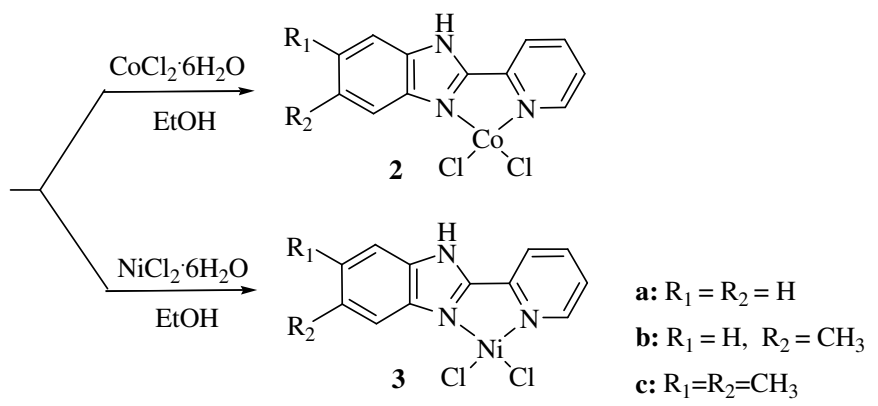

Scheme 1. Synthesis of ligands and complexes

\section{Result and Discussion}

\section{Synthesis and characterization}

The 2-(2-pyridyl)benzimidazole ligands 1a 1c were prepared as white or pale yellow solids in good yields by the condensation of one equivalent of the appropriate o-phenylenediamine with one equivalent of picolinic acid (Scheme 1). Compounds 1a 1c were characterized by microanalysis and ${ }^{1} \mathrm{H}$ NMR. Complexes of these ligands were synthesized by dissolving nickel or cobalt chloride in ethanol (Scheme 1), followed by addition of one equivalent of the ligand in ethanol. The complexes precipitated from the reaction solution. After washing with diethyl ether, the complexes $\mathbf{2 a} \sim \mathbf{c}$ and $\mathbf{3 a} \sim \mathbf{c}$ were obtained in good yield and high purity. The elemental analysis results revealed that the components of all complexes were in accord with the formula $\mathrm{MLX}_{2}$.

\section{Oligomerization of ethylene}

Upon treatment with methylaluminoxane (MAO), all of the complexes are active ethylene oligomerization catalysts. Table 1 lists their activity and molecular weight distribution of the oligomers. The nature of the metal center has a major influence on catalytic activities. In general, $\mathrm{Ni}$ (II) catalysts are more active than their corresponding $\mathrm{Co}(\mathrm{II})$ analogues under same condition. The most active $\mathrm{Ni}(\mathrm{II})$ catalyst is complex 3a $\left(1.14 \times 10^{5} \mathrm{~g}\left(\right.\right.$ ethylene $\left.\mathrm{mol}^{-1}(\mathrm{Ni}) \mathrm{h}^{-1}\right)$, While the Co(II) complexes are about $10^{3} \mathrm{~g}($ ethylene $) \mathrm{mol}^{-1}(\mathrm{Co}) \mathrm{h}^{-1}$ for oligomerization. Steric and electronic environmental around the central metal affected the catalytic activities. In the same condition, catalysts $(\mathbf{2 c}, 2 \mathbf{b}, 2 \mathbf{2} ; \mathbf{3 c}, 3 \mathbf{3 b}, 3 \mathbf{3})$ reveal that electron-donating group replacing the proton results in decreases in activity. The complex $\mathbf{2 a}(\mathbf{3 a})$ contains two methyl groups in the aryl rings and displays an activity of $5.78 \times 10^{3}\left(0.52 \times 10^{5}\right) \mathrm{g}($ ethylene $) \mathrm{mol}^{-1}(\mathrm{M}) \mathrm{h}^{-1}$, approximately complex $\mathbf{2 b}(\mathbf{3 b})$ with one methyl in the aryl ring with an activity of $6.25 \times 10^{3}\left(1.04 \times 10^{5}\right) \mathrm{g}($ ethylene $) \mathrm{mol}^{-1}(\mathrm{M}) \mathrm{h}^{-1}$. The same phenomenon was observed in our previously research. ${ }^{11-12}$ The oligomers are from $\mathrm{C}_{4}$ to $\mathrm{C}_{6}$. The substituents of the complexes affect distribution of the oligomers to some extent.

\section{Experimental}

MAO (1.4 $\mathrm{mol} \mathrm{l}^{-1}$ ) was purchased from Albemarle Corp (USA); Nickel or cobalt chloride and all of the $\hat{\imath}$-phenylenediamines were used commercially without further purification. $\mathrm{C}, \mathrm{H}, \mathrm{N}$ elemental analysis was performed using CHN-RAPID microanalyzer. ${ }^{1} \mathrm{H}$ NMR spectra were recorded on a Bruker spectrometer DMX-300, with TMS as the internal standard. Melting points were determined without 
further correction. Ethylene oligomerization results were recorded on a HP5890 Series II gas chromatograph (Hewlett-Packard).

\section{General procedure of synthesis ligands}

A mixture of $\hat{\imath}$-phenylenediamine $(5 \mathrm{mmol})$, picolinic acid $(5 \mathrm{mmol})$ and PPA $(4.5 \mathrm{~g})$ was stirred at $160 \bullet \mathrm{C}$ for $5 \mathrm{~h}$ under $\mathrm{N}_{2}$. After cooled to $100 \cdot \mathrm{C}$, it wos poured into $30 \mathrm{~mL}$ woter. The solution wos cooled and added $\mathrm{Na}_{2} \mathrm{CO}_{3}$ to adjust $\mathrm{pH}$ to 7 . The precipitated solid was filtered and recrystallized from AcOEt.

(1a): yield 61\%, m.p. $229-230{ }^{\circ} \mathrm{C},{ }^{1} \mathrm{H}-\mathrm{NMR}\left(\mathrm{CDCl}_{3}\right): \delta 10.63(1 \mathrm{H}, \mathrm{br}), 7.33-8.69(8 \mathrm{H}, \mathrm{m})$. Anal. Calc. for $\mathrm{C}_{12} \mathrm{H}_{9} \mathrm{~N}_{3}: \mathrm{C}, 73.83 ; \mathrm{H}, 4.65 ; \mathrm{N}, 21.52$. Found: $\mathrm{C}, 73.85 ; \mathrm{H}, 4.65 ; \mathrm{N}, 21.46 \%$.

(1b): yield 66\%, m.p. $165-166{ }^{\circ} \mathrm{C},{ }^{1} \mathrm{H}-\mathrm{NMR}\left(\mathrm{CDCl}_{3}\right): \delta 10.35(1 \mathrm{H}, \mathrm{br}), 7.13-7.89(7 \mathrm{H}, \mathrm{m})$, $2.52(3 \mathrm{H}, \mathrm{s})$. Anal. Calc. for $\mathrm{C}_{13} \mathrm{H}_{11} \mathrm{~N}_{3}: \mathrm{C}, 74.62 ; \mathrm{H}, 5.30 ; \mathrm{N}, 20.08$. Found: C, 74.80; H, 5.17; $\mathrm{N}, 20.05 \%$.

(1c): yield 71\%, m.p. $194-195{ }^{\circ} \mathrm{C},{ }^{1} \mathrm{H}-\mathrm{NMR}\left(\mathrm{CDCl}_{3}\right): \delta 10.15(1 \mathrm{H}, \mathrm{br}), 7.26-8.62(6 \mathrm{H}, \mathrm{m})$, $2.39(6 \mathrm{H}, \mathrm{s})$. Anal. Calc. for $\mathrm{C}_{14} \mathrm{H}_{13} \mathrm{~N}_{3}$ : C, 75.31; H, 5.87; N, 18.82. Found: C, 78.90; H, 7.89; $\mathrm{N}, 13.15 \%$.

\section{General procedure of synthesis complexes}

$\mathrm{MCl}_{2} 6 \mathrm{H}_{2} \mathrm{O}(0.20 \mathrm{mmol})$ in $5 \mathrm{~mL}$ enthanol and ligand $(0.20 \mathrm{mmol})$ in $5 \mathrm{~mL}$ ethanol were combined in a Schlenk flask. The mixture was stirred at room temperature for 10 hours, then the crude product was collected by filtration, washed with $3 \times 4 \mathrm{~mL}$ of $\mathrm{Et}_{2} \mathrm{O}$.

(2a): yield 93\%. Anal. Calc. for $\mathrm{C}_{12} \mathrm{H}_{9} \mathrm{~N}_{3} \mathrm{CoCl}_{2}$ : C, 44.34; $\mathrm{H}, 2.79 ; \mathrm{N}, 12.93$.

Found: C, 44.44; $\mathrm{H}, 2.75 ; \mathrm{N}, 12.96 \%$.

(2b): yield 85\%. Anal. Calc. for $\mathrm{C}_{13} \mathrm{H}_{11} \mathrm{~N}_{3} \mathrm{CoCl}_{2}$ : C, 46.05; H, 3.27; N, 12.39 . Found: $\mathrm{C}, 46.05 ; \mathrm{H}, 3.39 ; \mathrm{N}, 12.18 \%$.

(2c): yield 90\%. Anal. Calc. for $\mathrm{C}_{14} \mathrm{H}_{13} \mathrm{~N}_{3} \mathrm{CoCl}_{2}$ : C, 47.62; H, 3.71; N, 11.90 . Found: $\mathrm{C}, 46.40 ; \mathrm{H}, 3.76 ; \mathrm{N}, 11.63 \%$.

(3a): yield 85\%. Anal. Calc. for $\mathrm{C}_{12} \mathrm{H}_{9} \mathrm{~N}_{3} \mathrm{NiCl}_{2}$ : C, 44.37; $\mathrm{H}, 2.79 ; \mathrm{N}, 12.94$. Found: $\mathrm{C}, 44.16 ; \mathrm{H}, 2.85 ; \mathrm{N}, 12.62 \%$.

(3b): yield 87\%. Anal. Calc. for $\mathrm{C}_{13} \mathrm{H}_{11} \mathrm{~N}_{3} \mathrm{NiCl}_{2}$ : C, 46.08; $\mathrm{H}, 3.27 ; \mathrm{N}, 12.40$. Found: $\mathrm{C}, 46.53 ; \mathrm{H}, 3.21 ; \mathrm{N}, 12.25 \%$.

(3c): yield 90\%. Anal. Calc. for $\mathrm{C}_{14} \mathrm{H}_{13} \mathrm{~N}_{3} \mathrm{NiCl}_{2}$ : C, 47.45; $\mathrm{H}, 3.71 ; \mathrm{N}, 11.91$. Found: C, 47.20; H, 3.40; N, 11.67\%.

\section{General Procedure for Ethylene Oligomerization}

A flame dried three-neck round flask was vacuated-filled three times by nitrogen. Then ethylene was charged with $30 \mathrm{~mL}$ of freshly distilled toluene and stirred. At the room temperature, the aluminum cocatalyst MAO was added via syringe. The solution was stirred and the precatalyst complex (2a $\sim \mathbf{c}$ or 3a c, 10 i mol in $5 \mathrm{~mL}$ toluene) was added to the reaction mixture via syringe. After stirred under $1 \mathrm{~atm}$ ethylene pressure for $20 \mathrm{~min}$, the oligomerization was terminated by acidified ethanol. An aliquot of the reaction mixture was analyzed by gas chromatrography. Their activity and distribution of the oligomers were collected in Table 1.

Table 1. Activity and distribution for the oligomerization

\begin{tabular}{lllll}
\hline \multirow{2}{*}{ Complex } & \multirow{2}{*}{$\mathrm{Al} / \mathrm{Ni}$} & $\begin{array}{l}\text { Activity } \\
(\mathrm{g} / \mathrm{mol} \mathrm{h} \mathrm{atm})\end{array}$ & \multicolumn{2}{c}{ Distribution of oligomers (\%) } \\
\hline 2a & 500 & $7.50 \times 10^{3}$ & 62.03 & $\mathrm{C}_{6}$ \\
$\mathbf{2 b}$ & 500 & $6.25 \times 10^{3}$ & 69.09 & 37.97 \\
$\mathbf{2 c}$ & 500 & $5.78 \times 10^{3}$ & 72.74 & 27.26 \\
$\mathbf{3 a}$ & 500 & $1.14 \times 10^{5}$ & 80.44 & 19.56 \\
3b & 500 & $1.04 \times 10^{5}$ & 78.51 & 21.49 \\
3c & 500 & $0.52 \times 10^{5}$ & 72.65 & 27.35 \\
\hline \multicolumn{3}{c}{ Condition: $[\mathrm{Al}] /[\mathrm{Ni}]=1500$, toluene solvent, 1 atm of ethylene. }
\end{tabular}




\section{Conclusions}

In summary, we have synthesized a series of nickel and cobalt complexes, upon treatment with MAO, they are all active ethylene oligomerization catalysts. Comparing with cobalt complexes showing marginal activity, nickel complexes show good activity. The oligomers are $\mathrm{C}_{4}$ and $\mathrm{C}_{6}$.

\section{Acknowledgements}

We are grateful for financial supported from Hebei University.

\section{References}

1. Johnson L K, Mecking S, Brookhart M J. Am. Chem. Soc. 1996, 118, 267.

2. Mecking S, Johnson L K, Wang L, Brookhart M J. Am. Chem. Soc. 1998, 120, 888.

3. Johnson L K, Killian C M, Brookhart M J. Am. Chem. Soc. 1996, 117, 6414.

4. Killian C M, Tempel D J, Johnson L K, Brookhart M J. Am. Chem. Soc. 1996, 117, 6414.

5. Small B L, Brookhar M, Bennett M A J. Am. Chem. Soc. 1998, 120, 4049.

6. Britovsek G J P, Gibson V C, Kimberley B S, Maddox P J, McTavish S J, Solan G A, Stromberg A, White A J D, Williams D J Chem. commun. 1998, 849.

7. Wang C M, Friedrich S, Younkin T R, Li R T, Grubbs R H, Bansleben D A, Day M W Organometallics 1998, 17, 3149 .

8. Britovsek G J P, Bruce M, Gibson V C, Kimberley B S, Maddox P J, Mastroianni S, McTavish S J, Redshaw C, Solan G A, Stromberg A, White A J D, Williams D J J. Am. Chem. Soc. 1999, 121, 8728 .

9. Small B L, Brookhart M J. Am. Chem. Soc. 1998, 120, 7143.

10. Britovsek G J P, Mastroianni S, Solan G A, Baugh S P D, Redshaw C, Gibson V C, White A J D, Williams D J, Elsegood M R J Chem. Eur. J. 2000, 6, 2221.

11. Du J L, Li L J, Li Y F Inorg. Chem. Commun. 2005, 8, 246.

12. Du J L, Han L Q, Cui Y, Li J T, Li Y, Sun W-H Aust. J. Chem. 2003, 56, 703. 


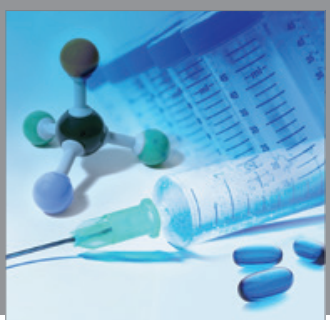

International Journal of

Medicinal Chemistry

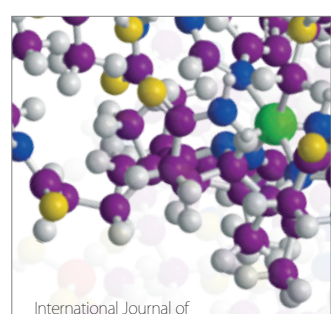

Carbohydrate Chemistry

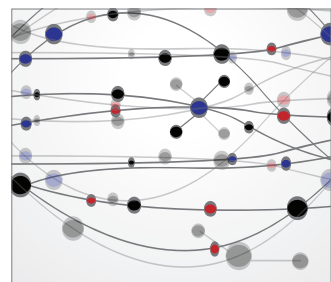

The Scientific World Journal
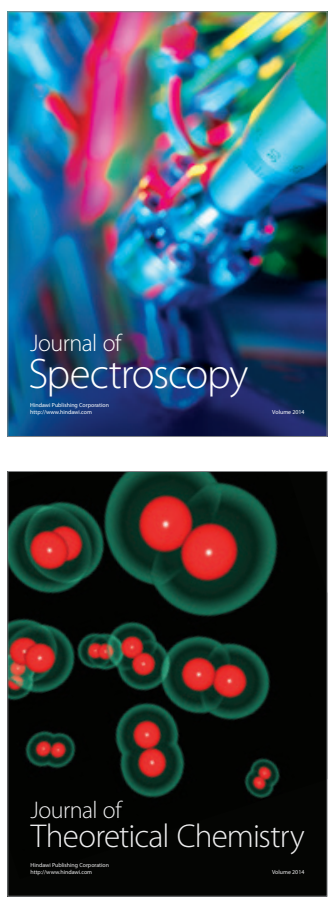
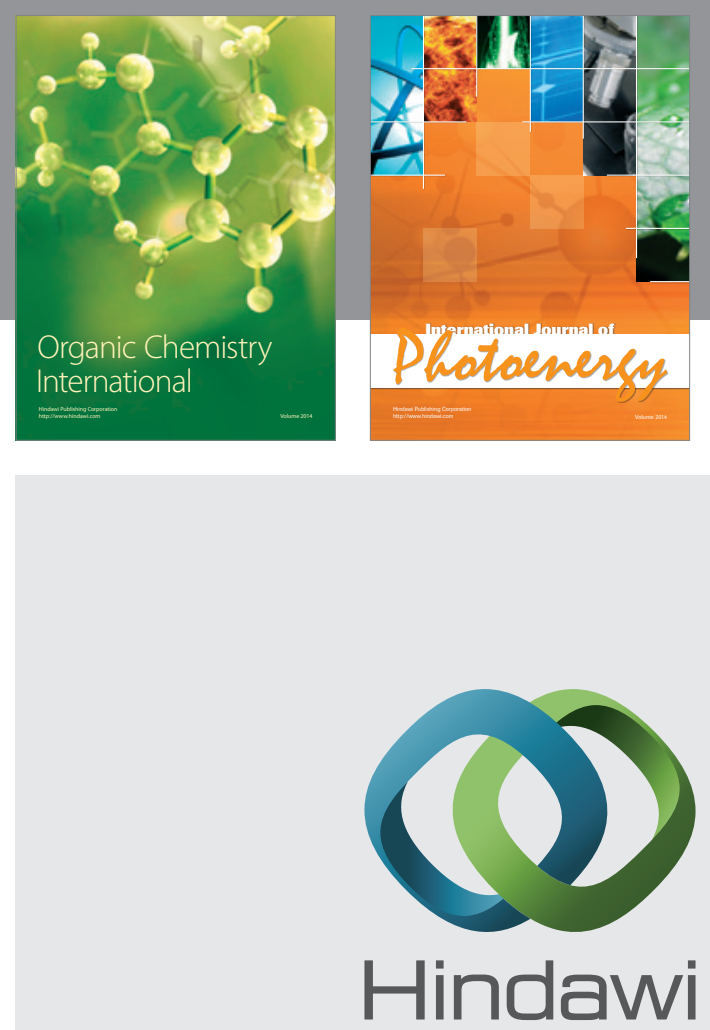

Submit your manuscripts at

http://www.hindawi.com
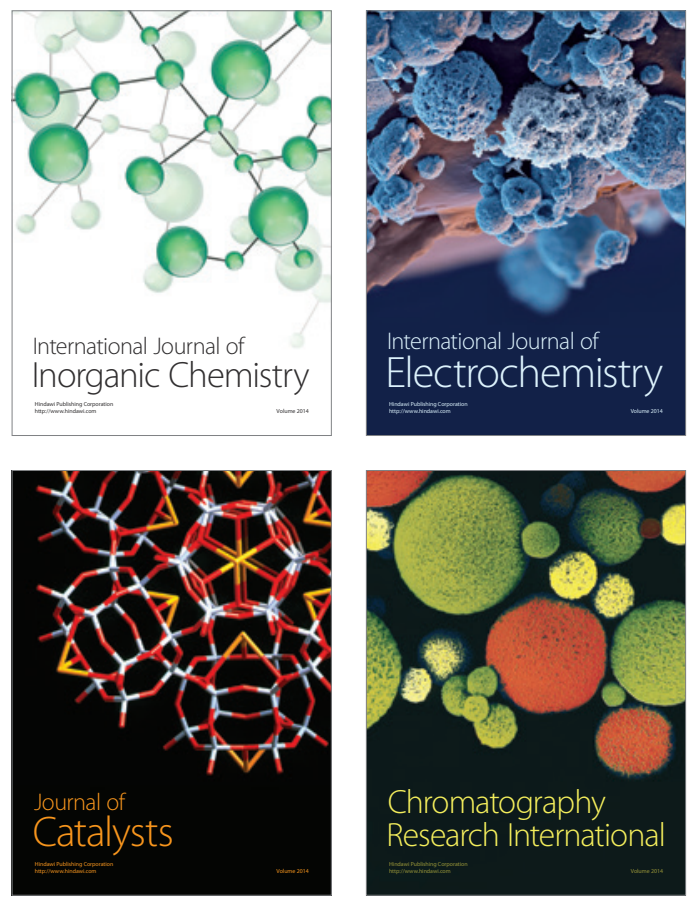
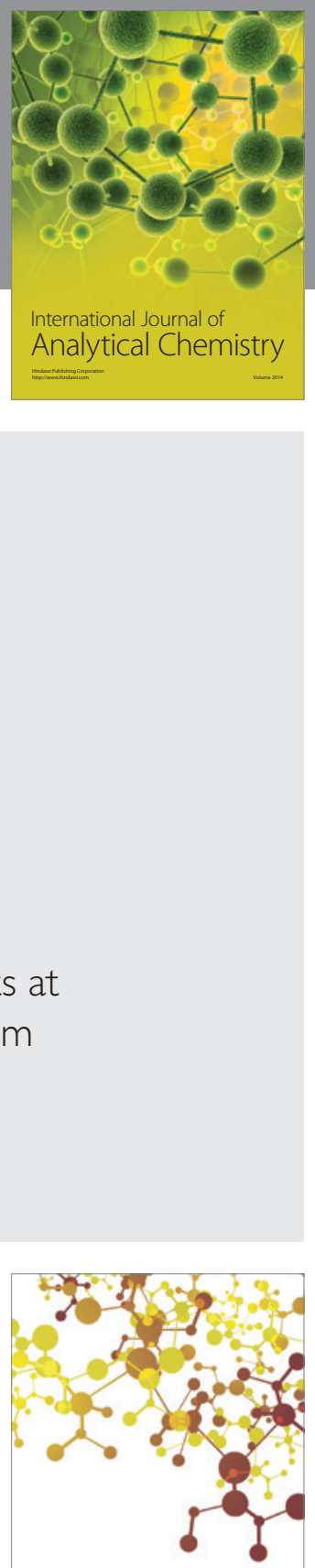

Journal of

Applied Chemistry
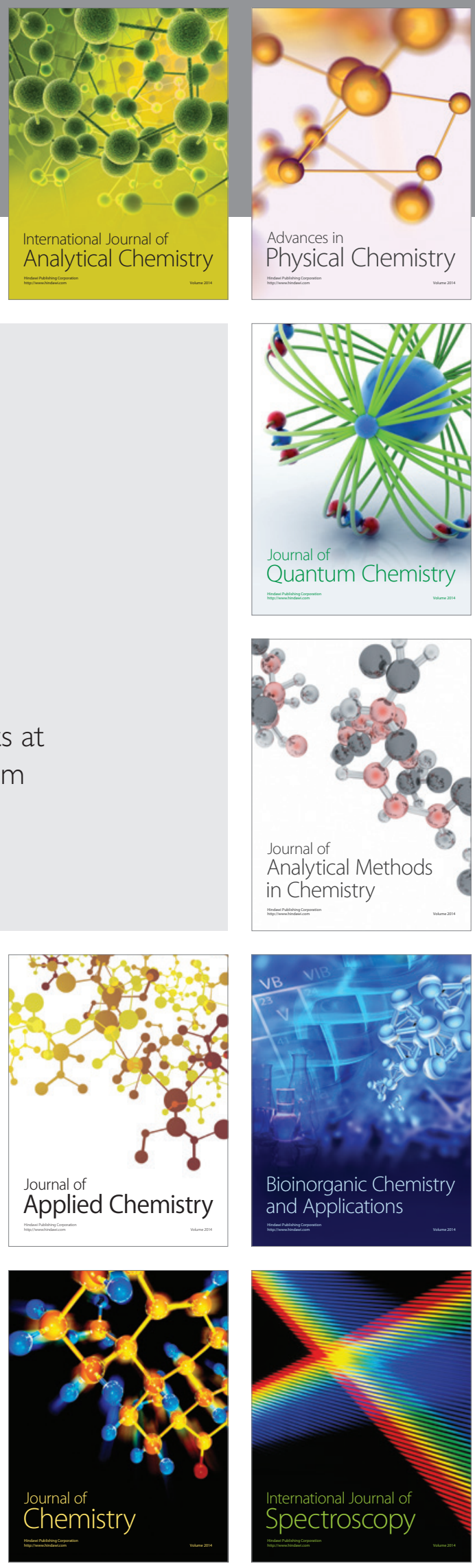